Культура как переход / перевод. «Небесное животное» Веры Павловой

\title{
Р. Грюбель
}

УНИВЕРСИТЕТ ОЛЬДЕНБУРГА

Аннотаџия. Рассматривается сборник стихов «Небесное животное» Веры Павловой как пример двух процессов становления культуры в современной России: перехода, т. е. изменения поэтического субъекта в культурном контексте, и перевода, т. е. изменения того, о чем стихотворение говорит. На фоне двух разных концептов возникновения культуры - модели Фрейда о сублимации, т. е. воздержания от половой деятельности в пользу духовной активности, и противостоящей ей модели Розанова с равноправной физической и ментальной креативной деятельностью показывается, что стиховая практика Павловой стоит намного ближе к концепции Розанова. При помощи этих концептов исследуются примеры из названного сборника Павловой и показывается, как поэтический субъект меняется самого себя в процессе культурного перехода и меняет предметы и приемы организации его текста. Рассматриваются переходы / переводы в отношении разных этнических культур, гендерных реляций, аксиологий и, например, религиозной и эстетической функций текстов и в конце статьи в отношении культуры апофатики.

Грюбель Р. Культура как переход / перевод. «Небесное животное» Веры Павловой // Критика и семиотика. 2019. № 1. С. 10-25.

ISSN 2307-1737. Критика и семиотика. 2019. № 1

(C) Р. Грюбель, 2019 
Ключевые слова: культура, трансфер, поэтический субъект, Вера Павлова, 3. Фрейд, В. Розанов.

УДК 81

DOI 10.25205/2307-1737-2019-1-10-25

Контактная информащия: Грюбель Райнер, Университет Ольденбурга (Ammerländer Heerstraße 114-118, Oldenburg, 26129, Deutschland, rainer.gruebel@uni-oldenburg.de)

\section{Что такое культура?}

Он <художник> есть модуль перевода из одного состояния в другое.

[Пригов, Эпштейн, 2004]

Слово и понятие «культура» (cultura) возникли более двух тысяч лет назад в Риме. Поначалу они обозначали обработку земли, которая позже в более узком смысле называлась и агрикультурой (agri-cultura). На примере земледелия, или агрикультуры, можно показать, что каждое действие культивации, каждое, так сказать, культурное действие человека содержит два процесса, которые часто производятся одновременно, но которые полезно отличать друг от друга для понимания сущности культуры: это переход и перевод. Предпосылкой обработки земли является представление человека о том, что земля не только что-то данное и неприкосновенное, что она находится перед человеком без возможности ее изменения, без возможности переделать ее, но и о том, что земля есть и что-то «заданное» человеку, т. е. имеется задача, которая требует от него активности, а именно ее обработки. В этом смысле культура есть переход, движение сознания человека от состояния не-действия в состояние действия, от пассивности в отношении мира к активности. Человек переходит от жизни собирателя к жизни пахаря.

Человек, который начинает заниматься земледелием, меняет свое место в мире, он становится не пассивной частью природы, а ее активным элементом, который трансформирует ее. В философии Спинозы и Бахтина эта позиция называется одновременно natura naturata т. е. «сотворенная природа», и natura naturans, т. е. «природа творящая». Как сотворенная природа человек совпадает с растениями и животными, а как творящая природа он соответствует Богу. Русский мыслитель Николай Федоров [1906] сказал, что задача человека состоит именно в усовершенствовании не до конца сотворенного Богом мира. Каждый творческий акт, каждое 
действие в культуре, каждая приготовленная еда, каждое сказанное слово, каждое написанное стихотворение подразумевают переход человека из существа сотворенного в существо сотворенное $u$ творящее. Человек, который обрабатывает землю, становится крестьянином, человек, который готовит блюдо, становится поваром, человек, который сочиняет стихи, становится поэтом.

Кстати, и всякая не-приготовленная еда, каждое не-сказанное слово, всякое не-написанное стихотворение в ситуации, в которой предполагается их приготовление, высказывание или писание, является таким же творческим актом. Это очень важно в контексте охраны природы или апофатики, когда именно не-действие является самым важным культурным действием. Тогда и не-активность человека предполагает его переход, его трансгресс от пассивности традиционного действия в активность нетрадиционного не-действия. В таком смысле не-написание статьи о Гитлерехудожнике может быть вкладом в борьбу с фашизмом.

Другая грань культуры - это перевод. В этом случае изменение происходит не в отношении культуры творящего человека, культурного агента, но в отношении его предмета, например земли. Агрикультура превращает природу в поле, естественную землю в полевые угодья. В этом смысле культура не только трансгрессия, не только переход, но и трансформация, перевод. Варение трансформирует более или менее естественные продукты в искусственное блюдо, сочинение стихов переводит мысли, чувства, переживания человека и сырье языка в смысловое и языковое целое поэтического текста. Этот перевод действует одновременно и на переводчика: он более или менее осознает, что переводит явления в их художественные эквиваленты. И он замечает, что становится поэтом. Это значит, что работа культуры приводит и к трансгрессии ее работника. Кстати, именно этот переход, при котором возникает, например, поэтический субъект, один из самых интересных процессов современной культуры.

Это проявляется, например, в том, что во время перехода позднего структурализма в деконструктивизм и неоавангардизма / соцреализма в постмодернизм функция автора подвергалась сомнению. Сравни тезис Роланда Барта [1994] о том, что «автор умер», и современные дискуссии о функции и статусе поэтического субъекта. Поэтический субъект является именно внутритекстовой точкой пересечения между переводом и переходом как транзитивных культурных процессов поэтического текста ${ }^{1}$.

В развитых культурах большинство культурных переводов состоит в трансформации уже существующих в той или иной форме продуктов культуры в другие. Наглядный пример этого трансфера культурных явлений в другие в диалоге культур - интертекстуальность, теория которой сама же результат межкультурного диалога, в данном случае русского,

\footnotetext{
${ }^{1}$ Cp. Stahl (Hg.).
} 
болгарского и французского (тогда надо, наверное, напомнить о болгарском происхождении Кристевой, хотя некоторые могут думать, что это будет не очень политкорректно [Ильин, 1999, с. 204-206]). Итак, чтобы вернуться назад, к нашему начальному примеру, к культуре как переводу принадлежит не только природа, сырая земля, но и поле, полевые угодья. Например, мы можем не только перевести обработанную землю в другое качество и растить овощи сегодня там, где в прошлом году росла кукуруза, но мы можем и превратить ее в необработанную землю, в пустырь. Мы можем трансформировать культивированный лес, плантаж, как бы назад, в девственный лес. Уничтожение культурных монументов тоже есть акт культурного перевода, в случае снятия памятников фашизма или сталинизма это был положительный акт, а в случае разрушения ассирийских памятников так называемым исламским государством в Пальмире - акт варварский.

Другой пример ранней культурной деятельности человека - скотоводство. В рамках животноводства человек влияет на естественную репродукцию животных. Эта активность сопровождается приручением животных. Кстати, название интересующей нас книги, «Небесное животное», говорит о том, что в нем мы имеем дело более с активностью, так сказать, животновода, чем пахаря. Перед тем же, как мы приступим к разбору книги Веры Павловой [1977], мы должны рассмотреть две теории возникновения культуры начала того века, в конце которого писались ее стихи, попавшие в сборник «Небесное животное».

\section{Две теории двадцатого века о возникновении культуры}

В начале двадцатого века в России и в Австрии возникли две теории o возникновении культуры. Первая создана в Петербурге как ответ на представление православной церкви о роли пола в жизни человека. Другая, более известная, появилась независимо от первой на десятилетие позже в Вене как часть психиатрической практики. Начинаем со второй, потому что она более известна и, как нам кажется, на ее фоне специфика первой выступает нагляднее.

Зигмунд Фрейд [2009] развивал свою теорию культуры на основе концепта психической экономии. По его убеждению, культурные акты человека предполагают временный отказ от траты половой энергии. Этот отказ он назвал «сублимацией». При помощи сублимации, т. е. перевода творящей энергии из физиологии полового действия в психологию духовного творчества, человек может сотворить, например, художественные произведения. При этом человек переводит созидательную энергию из сферы природы в сферу культуры. Фрейд изложил свою теорию сотворения культуры на примере Леонардо да Винчи, у которого не было детей, что, 
по мнению Фрейда, в значительной степени свидетельствует об отказе этого художника от половой жизни.

В отличие от Фрейда, за несколько лет до возникновения и публикации его экономической теории производства культуры, русский философ, журналист и писатель Василий Розанов [1995; 2008] заложил основу иной концепции возникновения культуры - не как соревнования друг с другом конкурирующих физиологической и психологической активности, но на основе сосуществования биологической и духовной активности человека. По Розанову, нет конкуренции и даже нет принципиальной разницы между физической и ментальной креативной деятельностью человека. Итак, в основе его теории культуры лежит не концепт ограниченной энергии человека, которую тот может затратить или на биологическую саморепродукцию, или на духовное творчество, а представление о постоянном человеческом творчестве, которое может привести либо к рождению ребенка, либо к сотворению художественного сочинения. При этом у Розанова в отличие от Фрейда нет и аксиологической иерархии между зачатием детей и сотворением артефактов.

Чтобы подчеркнуть эквивалентность создания ребенка и художественного произведения, Розанов даже назвал творение артефакта его рождением и рассматривал его как женскую активность сочинителя, хотя он как мыслитель, который часто менял свои убеждения, иногда и рассматривал это действие как мужскую деятельность. Розановская теория креативности человека, о которой американский славист Adam Ure опубликовал интересную книгу Vasilii Rozanov and the Creation [2011], служила в то же время его освобождением от примера философии Леонтьева, согласно которой верх человеческого поведения не половое или художественное сотворение, но аскеза. По Розанову, аскеза воспрепятствует и биологической репродукции человека, и его художественному творчеству.

Когда Розанов познакомился с теорией Фрейда, а именно с ее экономическим концептом альтернативы - или физиологической, или ментальной - создания человека, он указал на примеры таких людей, как Лев Толстой, у которого много детей и большая художественная продуктивность, т. е. у графа высокий уровень половой активности совпадает с огромной ментальной продуктивностью [Grübel, 2019, S. 275-278, 344].

По теории Фрейда человек как творец культуры переходит из области физиологии в область ментальных явлений. В то же время он переводит личные переживания в общечеловеческий опыт. По концепции же Розанова человек может свободно, т. е. без принципиальной перемены, вступить в репродуктивное действие, будь то зачатие детей или творение художественного произведения. Для Розанова культура является осуществлением созидательной силы человека, будь то сила физиологическая или духовная. Кстати, эта аналогия, это равноправие и эта равноценность биологической и ментальной креативности человека отличает концепт любви Ро- 
занова и от идеи ценностной иерархии феноменов отрицательной или сомнительной половой любви, положительного, хотя еще чувственного эроса с отказом от половой активности, и чисто ментальной «агапе», т. е. любви к богу, в философии Соловьева ${ }^{2}$. Как творящее с любовью существо человек, по Розанову, находится на одном уровне с Богом [Грюбель, 2014]. Это отличает его концепцию и от идеи Ницше о смерти Бога. Для Розанова Бог не умер, он становился партнером и собеседником человека.

\section{Сходство концепции любви у Веры Павловой с теорией культуры Розанова}

В неозаглавленном стихотворении, состоящем из пяти стихов, входящем в сборник «Совершеннолетие» и начинающемся словами «а может быть...», поэтический субъект воспроизводит образ телесной активности коллективного «мы». Назвать производство (небесных) звуков «рождением», обозначить его словом, указывающим изначально на биологическое явление репродукции, подразумевает и ссылку на книгу Ницше Рождение трагедии из духа музыки [1912]. Как и у Розанова (и у Ницше), лирическое Я у Павловой ставит на один уровень креативность человека и Бога. Это, конечно, противоречит духовному канону православной церкви. В этом тексте не-слышимость звуков тел людей, занятых половым актом, указывает на не-слышимость для человека музыки сфер в философии Аристотеля [1981], в его трактате «О небе» (Пєрі̀ oủ $\alpha v o \tilde{, ~ I I .9): ~}$

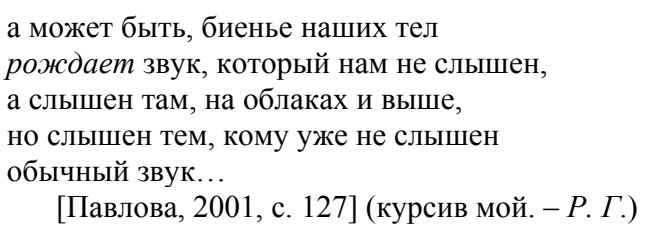

Уподобление движения человеческих тел движению тел небесных объясняет и значение названия сборника - «Небесное животное». Человек

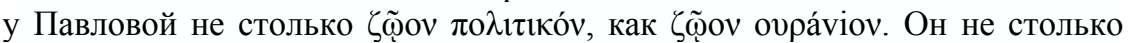
политическое существо, сколько существо космическое. Физиологическая активность человека, которая самим словом «рождество» отождествляется с небесным созиданием, как и движение планет, самому человеку не слышна, но она слышна небесным существам, которым с их стороны не слышны же звуки без творящей основы.

Если кто-то сомневается в том, что выражение «биение тел» в тексте Павловой имеет сексуальное значение, тому это прояснит следующее сти-

\footnotetext{
${ }^{2}$ Полный список ступеней любви у Соловьева: 1) дьявольски-адская, 2) животно-телесная любовь, 3) человеческая эротика для репродукции человечества в браке, 4) аскетический отказ от телесной любви, 5) обожествление любви к агапе.
} 
хотворение из того же сборника (прошу прощения за откровенный язык автора):

О чем бы я не писала, пишу о ебле.

И только когда я пишу о самой ебле,

то кажется, что пишу совсем не о ебле.

Вот почему я пишу только о ебле ${ }^{3}$

[Павлова, 1977, с. 223] ${ }^{4}$.

При этом мы встречаемся в данном стихотворении с фигурой отрицания, которую можно относить к концепту вытеснения (Verdrängung) Фрейда, но так как у Павловой она поставлена с головы на ноги, она здесь даже антифрейдистская. Кстати, рефлексия автора о половом действии переводит самое это действие в акт культуры, в творчество и способствует этим актом тому, что сексом занятый человек сам переходит из биологического животного в человека культуры.

\section{Фигуры культурного перехода (трансгрессии) в сборнике «Небесное животное»}

Если близость концепции культуры Павловой к философии культуры Розанова ${ }^{5}$ достаточно очевидна, то примеры перехода поэтического субъекта в новое культурное состояние в большинстве стихотворений Павловой менее ясны. Эта меньшая ясность вытекает из сложности позиции автора и поэтического субъекта в поэтическом мире.

Первым примером нам служит стихотворение Corps («Тело»), которое в рамках цикла Blasons («Гербы») печатается в середине книги не с обычным горизонтальным, а с вертикальным положением стихов. Конечно, такое вращение книги на $90^{\circ}$ при чтении текста указывает на ожидаемую от читателя общую мировую переориентацию в процессе рецепции книги.

\footnotetext{
${ }^{3}$ Вопрос, поставленный профессором лингвистики после чтение этого доклада в Институте языкознания Российской академии наук в Москве, существует ли вообще поэт с именем Вера Павлова, и его указание на то обстоятельство, что русская женщина не говорит о предметах пола в обществе, можно понять как доказательство того, что поэзия Веры Павловой на самом деле производит перевод в русской культуре, и именно этим поэтический субъект ее стихотворений сам исполняет культурный переход.

${ }^{4}$ В дальнейшем стихи из этого сборника цитируются с указанием только страниц.

${ }^{5}$ Близость концепции тела Павловой к творчеству Василия Розанова замечена до сих пор лишь в отношении как бы случайного совпадения: «Мы не утверждаем сознательной литературной переклички Павловой с Розановым» [Подрезова, 2010, c. 98].
} 
Поэтический субъект называет тело говорящего Я сначала как единственную его собственность, которая дана ему творцом в виде обнаженного явления. Это значит, что тело человека с самого начала - художественное произведение. Однако такое свойство нагое тело получает только в процессе размышления и писания стихов о нем с названием Le corps. Причем французское название придает предмету тела всю семантическую ауру французской культуры. Мы как примеры вспоминаем творчество скульпторов Камиллы Клодель и Огюста Родена. Однако, согласно стихотворению Павловой, это данное человеку произведение, его, так сказать, божественная скульптура, со временем теряется:

Le corps

Что мне терять на земле, кроме этого тела?

И - уже теряю.

Тело уже поредело.

Но оно и сейчас - у меня ведь судьба не дура! -

удача

(c. 112)

всевышнего мастера обнаженной натуры. <..>

Женское лицо, о котором говорится в тексте, предстает в воспоминании лирического Я в виде некоего либретто сновидения, т. е. текста оперы, который, однако, в этом случае остается без тех слов, которые женщина пела вместе с мужчиной во время любви:

Подружка! Кто научил тебя

вовремя поднимать ножки и,

кончая, кричать, окликать

отлетающую душу?

Никто не учил.

Природа

Природа, меня наделившая тонким запястьем, чтобы сошлись на нем намертво

мужские пальцы,

природа, меня наделившая телом

компактным и белым, чтобы

стелиться ему по земле под тяжелым телом мужчины,

которого пишет влюбленная память

в сновиденьи,

натура которого дышит под боком,

в сновиденьи,

либретто которого вместе распели...

Вокализ андрогина и взбитые сливки постели

(c. 113-114, курсив мой. - Р. Г.)

Трансгрессия здесь производится в работе памяти и написания стихотворного текста. При этом следует обратить внимание на то, что сама природа, которая дала человеку его тело, здесь выступает и как doctrina, как 
учение, в центре которой слова с корнем «род»: роды, родить и рождение. Во-вторых, замечательно, что вокализ, т. е. текст этого либретто, в отличие от самого текста стихотворения не содержит никаких слов, а состоит только из звуков, и что в конце текста половое противопоставление женщины мужчине, как в андрогине, снято ${ }^{6}$.

Как второй пример перехода мы рассматриваем стихотворение, в котором поэтический субъект говорит о тех жизненных задачах, которые он мог бы выполнить, но не выполнил. Остается лишь одна реализованная им позиция. Но эту позицию он обозначает с такой иронией и таким юмором, которые характерны именно для того художника, о котором оно говорит, для Пригова. Сам же текст реализует то потомство, которое стихи называют именем и при помощи четырех риторических фигур литотес. Переход здесь выступает как выбор человеком возможностей жизненного пути, карьеры, который в итоге приводит к существованию поэта-художника:

Во мне погибла балерина.

Во мне погибла героиня.

Во мне погибла лесбиянка.

Во мне погибла негритянка.

Как много их во мне погибло!

И только Пригов жив-здоров

(c. 201).

Если все четыре нереализованные возможности (кстати, Розанову хотелось написать свою вторую философскую монографию - вслед за книгой о «Понимании» - именно о возможности) оформлены как правильно построенные четырехстопные ямбы с точными рифмами, то эти рифмы отсутствуют в последних двух стихах, которые говорят о реально выбранном пути. Рифмуются нереализованные возможности, а у реальной карьеры нет звукового совпадения.

Третий и последний пример реализации трансгрессии дан в сравнительно коротком стихотворении без названия из того же сборника, которое содержит только восемь слов. Первые два стиха этого текста, «Идет / мужик», повторяют начало многих русских анекдотов, как, например, «Идет мужик по кладбищу ночью». В отличие же от этих юмористических текстов поэтический субъект стихотворения Павловой передает в своих очень коротких, одно- или двухслоговых словах развитие человека через смерть в другое состояние, в котором, однако, его движение совпадает с первоначальным. Итак, этот текст как бесконечный рассказ можно, приближаясь

${ }^{6}$ Эта андрогинность связывает гендерный концепт поэтического субъекта больше с моделью любви символистов, чем Розанова (1912), который, например, в книге Люди лунного света настаивал на гетеросексуальной основе любви (ср. [Матич, 2008]). 
к его окончанию, начать с начала. Граница между этим светом и тем светом ниже обозначена мной при помощи прямой линии:

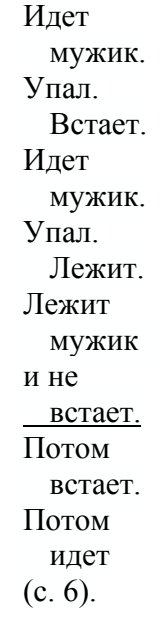

Примечательно здесь (и это отличает эти стихи от обычных бесконечных рассказов), что повтор здесь начинается уже с пятого слова, глагола «идет», которое в то же время олицетворяет сам переход. Таким образом, переход реализуется как переход от перехода к переходу. Кстати, это представление о бесконечном ходе противоречит как марксистскому и советскому положению о коммунизме как конечной стадии истории человечества, так и тезису Фукуямы о конце истории.

\section{Фигуры культурного перевода в сборнике «Небесное животное»}

Трансформация, или перевод как культурная стратегия встречается в стихах Павловой нередко в диалогической форме. В одном стихотворении, начинающемся с вопроса «Попался, голубчик?», этот перевод дается как инверсия библейского рассказа о сотворении человека. В отличие от книги Моисея, по которой женщина Ева творится Богом из ребра мужчины Адама, у Павловой человек творится из клетки женщины Евы:

Попался, голубчик? Ты в клетке,

ты в каждой моей клетке,

могу из одной своей клетки

создавать тебя, как голограмму,

всего тебя - из миллиграмма,

из Евиной клетки - Адама

(c. 19). 
Во-первых, этот переворот изменяет традиционную гендерную иерархию: приоритет теперь принадлежит Еве. Если в ранее рассмотренном тексте о теле, а в какой-то форме и в стихотворении, где поэтический субъект отождествляется с Приговым, противопоставление гендеров нейтрализовалось, то в данном стихотворении эта оппозиция обращается вспять. Во-вторых, меняется манера пере-творения: в мире стихотворения это не только биологический процесс мультипликации человека из яйцеклетки, но и редупликация и диверсификация при помощи голограммы. Возникает не только новое биологическое существо, но и оптическая иллюзия другого человека. В этом смысле стихотворение дает кроме альтернативы к религиозному представлению о сотворении человека, т. е. кроме биологического концепта размножения, и модель сотворения стихового текста. В конце текста ведь создан стиховой Адам.

В другом случае перевода, в восьмистишии, которое начинается цитатой из перевода Гейне Лермонтовым, «На севере диком...», поэтический субъект сначала отказывается от мнения, что перевод стиха «На севере диком...»- мотив, взят из Гейне. Конечно, в узком смысле и даже исторически проверяемо, что стих Лермонтова является переложением из Гейне:

Гейне

Ein Fichtenbaum steht einsam

Im Norden auf Kahler Höh'

[Heine, 1827, c. 173]

\section{Лермонтов}

На севере диком стоит одиноко

На голой вершине сосна

[Лермонтов, 1961, с. 512]

Но в широком смысле любовных песен, о которых говорит лирическое «я» этого стихотворения, мотив неразделенной любви - это на самом деле скорее мотив Сапфо, которая, по преданию, совершила самоубийство, сбросившись с Левкадских скал из-за неразделенной любви к паромщику Фаону. Это значит, что смысловое соответствие творится не столько совпадением слов, как в поверхностной цитате, сколько глубинным смыслом литературного мотива. Если в этом контексте вообще может быть принят во внимание Гейне, то, аргументируют лирическое «я» его стихи о Лорелее, где, однако, наоборот, тонет шкипер маленького судна на реке Рейне, который не может отвести свой взгляд от прекрасной девушки.

Как известно, уже в переводе Лермонтова имеется гендерная «замена», потому что у Гейне на севере стоит Fichtenbaum (сосна), т. е. в немецком языке предмет мужского рода, который там противопоставляется дереву женского рода - Palme (пальма), а у Лермонтова слово женского рода сосна противопоставляется также слову женского рода пальма. Эту гендерную игру, в которой Лермонтов создает вместо гетерофильного гомофильное соотношение, поэтический субъект Павловой продолжает противопоставлением поэтессы-женщины Сапфо поэту-мужчине Гейне:

«На севере диком...»- Сапфо, а не Гейне.

Ты - пальма. И юг твой, как север мой, дик. 
А если из Гейне, то пенье на Рейне, дуэт лорелей. А сплочая сплетенье Наталья, пойдем в хоровод эвридик, которым орфеи и лели - до фени:

с нездешнею нежностью, без сожаленья покажем им розовый острый язык! (c. 215)

Снова мы здесь встречаем культурный перевод: во-первых, гендерный перевод с точки зрения мужчины на женскую точку зрения и, во-вторых, эстетический перевод из ситуации трагической в положение комическое. На место смертельного конца поэтический субъект ставит грубо юмористический жест показывания языка. Читатель не должен забывать о том, что Сапфо создала сказочную женскую гомофильную культуру. Итак, именно неточный (но очень точно рассчитанный) перевод из немецкой и греческой культур рождает оригинальный русский текст как у Лермонтова, так и у Павловой. Это показывает, что культура как перевод подразумевает неизбежную и намеренную продуктивную неточность.

Стихотворение, которое начинается словом «Поэзия», а со знаком двоеточия возбуждает ожидание, что оно дает определение этого слова, говорит и на самом деле о функции стихов ${ }^{7}$. В начале оно определяет эту функцию как «ложь», однако как «ложь в спасение идеи», а потом как перевод предмета из отрицательного положения гибели, уничтожения, опасности, беды и / или греха в положительное положение существования, безопасности, счастья и/или блаженства. Посредством поэзии воскрешается представление о божественной природе слова, высказанное в начале Евангелия от Иоанна: «В начале было Слово, и Слово было у Бога, и Слово было Бог». Однако субъект текста обозначает поэзию не как правду, а как ложь, но такую ложь, которая может спасать представление о божественной природе слова. Именно таким образом она делает возможным и воскресение человека:

Поэзия: ложь во спасение

идеи, что слово - бог ${ }^{8}$,

что легкое слово гения

спасительно, как вдох

\footnotetext{
${ }^{7}$ Не исключено, что Павловская указывает на традицию искусства употребления знаков препинания в «Опавших листьях» Розанова. Если это так, то она перевела это искусство из поля прозы в поле поэзии. Ср. [Федякин, 2014].

${ }^{8}$ Написание слова «бог» в постсоветском контексте со строчной буквы показывает, что в этом контексте лирическое Я имеет в виду не только Бога христианской веры, но всякий концепт бога. Таким образом изречение евангелиста Иоанна обобщается, и стихотворение переходит из поле искусства религии в поле религии искусства.
} 


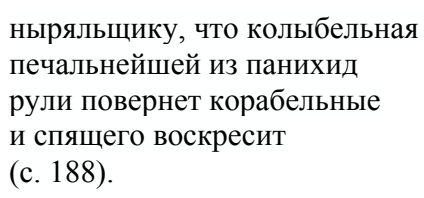

Этот текст подразумевает возможность того, что поэт при помощи поэтического слова становится спасителем, мессией, а это в горизонте иудейской и христианской культур самый далеко идущий переход человека в мире. На самом деле это переход в мир иной, а именно в тот мир, из которого, по словам Зосимы из Братьев Карамазовых, взято семя людей этого света. Бог взял семена из миров иных и посеял на сей земле и взрастил сад свой [Достоевский, 1976, с. 290].

В таких стихотворениях поэтический субъект Павловой совершает перевод культуры из этого мира в мир, для обозначения которого у нас отсутствуют слова. Так, в другом тексте (это наш последний пример), он называется выражением «тот свет» - «фигурой речи», т. е. традиционной манерой говорения, которому только очень условно соответствует настоящий предмет. В этом шестистишии говорящее «я» наталкивается на границу возможности выражения:

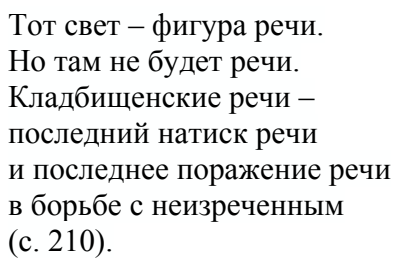

Переводя стихотворную речевую культуру через границу высказываемого (и это самый большой шаг, возможный на этом поле), поэтический субъект этого текста переводит и нас в сферу того мира, в котором, по его словам, «не будет речи». А как сказал философ Витгенштейн в конце своей книги «Логико-философский трактат» [1958] (Tractatus logico-philosophicus), «о чём невозможно говорить, о том следует молчать». Итак, и мы умолкнем.

\section{Список литературы}

Аристотель. О небе // Аристотель. Соч.: В 4 т. / Пер. И. Д. Рожанский. M., 1981. T. 3.

Барт Р. Смерть автора // Барт Р. Избранные работы: Семиотика. Поэтика / Пер. З. Б. Зенкина. М., 1994. С. 384-391.

Витгенштейн Л. Логико-философский трактат / Пер. с нем. И. С. Добронравова, Д. М. Лахути. М., 1958. 
Грюбель Р. Василий Розанов и Ветхий Завет: Рецепция Песни Песней, культуры семи и семьи и основы симметричной религии // Anzeiger für Slavische Philologie XLII. 2014. C. 29-52.

Достоевский Ф. М. Братья Карамазовы // Достоевский Ф. М. Полн. собр. соч. Л., 1976. Т. 14.

Ильин И. П. Интертекстуальность // Современное зарубежное литературоведение / Ред. И. П. Ильин, Е. А. Цурганова. М., 1999. С. 204-210.

Лермонтов М. Полн. собр. соч. М.; Л., 1961. Т. 1.

Матич $O$. Эротическая утопия. Новое религиозное сознание и fin de siècle в России. М., 2008.

Ницие Ф. Рождение трагедии из духа музыки. СПб., 1912.

Павлова В. Небесное животное. М., 1977.

Павлова В. Совершеннолетие. М., 2001.

Подрезова Н. Н. Категория телесности в лирике Веры Павловой // Сибирский филологический журнал. 2010. № 2. С. 9-98.

Пригов Д. А., Эпитейн М. Попытка не быть неидентифицированным. 2004. Ч. 2. URL: https://epub3.livejournal.com/63401.html (дата обращения 12.10.2018).

Розанов B. Семья как религия // Розанов В. В. В мире неясного и нерешенного. М., 1995. С. 67-81.

Розанов B. Религия и культура // Розанов В. В. Религия и культура. М., 2008. C. $7-242$.

Федоров Н. Ф. Философия общего дела. Верный, 1906. Т. 1.

Федякин С. Р. Художественная проза Василия Розанова: жанровые особенности. М., 2014.

Фрейд 3. Введение в психоанализ. М., 2009.

Grübel R. Wassili Rosanow. Ein russisches Leben vom Zarenreich bis zur Oktoberrevolution. Münster: Aschendorff, 2019.

Heine H. Buch der Lieder. Hamburg: Hoffmann und Campe, 1827.

Ure A. Vasilii Rozanov and the Creation: The Edenic Vision and the Rejection of Eschatology. London, New York: Continuum, 2011.

\section{Article metadata}

Title: Culture as a Transition / Translation. "Heavenly Animal" by Vera Pavlova

Author: R. Grübel

Author's e-mail: rainer.gruebel@uni-oldenburg.de

Author's affiliation: Institute of Slavonic Studies University of Oldenburg (Germany) 
Abstract. The article considers Vera Pavlova's collection of poems "The Heavenly Animal" as an example for two processes of the formation of culture in recent Russian history: transition, i.e. changes of the poetic subject in its cultural context and translation, i.e. changes of what the poem is talking about and how it does it. Against the background of two different concepts of the emergence of culture, Freud's model of sublimation, that is, abstinence from sexual activity in favor of spiritual activity and the opposing model of Rozanov with equal physical and mental creative activity, it is shown that Pavlova's verse practice is much closer to Rozanov's concept. With the help of these concepts, examples from the mentioned collection by Pavlova are investigated and it is shown how its poetic subject changes itself in the process of cultural transition and how it changes objects and methods of organizing its text. Transitions / translations are considered in relation to different ethnic cultures, gender relations, axiologies, and (for example, religious and aesthetic) functions of texts and at the end also into the apophatic culture.

Reference literature (in transliteration):

Aristotle. O nebe. In: Aristotle. Sochineniya. In 4 vols. Transl. by I. D. Rozhansry. Moscow, 1981, vol. 3. (in Russ.)

Bart R. Smert avtora. In: Bart R. Izbrannye raboty: Semiotika. Poetika. Transl. by Z. B. Zenkin. Moscow, 1994, p. 384-391. (in Russ.)

Dostoevsky F. M. Brat'ya Karamazovy. In: Dostoevsky F. M. Polnoe sobranie sochineniy. Leningrad, 1976, vol. 14. (in Russ.)

Fedorov N. F. Filosofiya obshchego dela. Vernyi, 1906, vol. 1. (in Russ.)

Fedyakin S. P. Khudozhestvennaya proza Vasiliya Rozanova: zhanrovye osobennosti. Moscow, 2014. (in Russ.)

Freud Z. Vvedenie v psikhoanaliz. Moscow, 2009. (in Russ.)

Grübel R. Vasilii Rozanov i Vetkhii Zavet: Retseptsiya Pesni Pesney, kultury semi isem'i i isnovy simmetrichnoy religii. Anzeiger für Slavische Philologie XLII, 2014, S. 29-52. (in Russ.)

Grübel R. Wassili Rosanow. Ein russisches Leben vom Zarenreich bis zur Oktoberrevolution. Münster: Aschendorff, 2019.

Heine H. Buch der Lieder. Hamburg: Hoffmann und Campe, 1827.

Ilin I. P. Intertekstualnost. In: Ilin I. P., Tsurganova E. A. (eds.). Sovremennoe zarubezhnoe literaturovedenie. Moscow, 1999, p. 204-210. (in Russ.)

Lermontov M. Polnoe sobranie sochineniy. Moscow, Leningrad, 1961, vol. 1. (in Russ.)

Matich O. Eroticheskaya utopiya. Novoe religioznoe soznanie i fin de siècle v Rossii. Moscow, 2008. (in Russ.)

Nitsche F. Rozhdenie tragedii iz dukha muzyki. St. Petersburg, 1912. (in Russ.)

Pavlova V. Nebesnoe zhivotnoe. Moscow, 1977. (in Russ.)

Pavlova V. Sovershennoletie. Moscow, 2001. (in Russ.) 
Podrezova N. N. Kategoriya telesnosti v lirike Very Pavlovoy. Siberian Journal of Philology, 2010, no. 2, p. 9-98. (in Russ.)

Prigov D. A., Epstein M. Popytka ne byt' neidentifitsirovannym. 2004, pt. 2. URL: https://epub3.livejournal.com/63401.html (accessed 12.10.2018). (in Russ.)

Rozanov V. Religiya i kultura. In: Rozanov V. V. Religiya i kultura. Moscow, 2008, p. 7-242. (in Russ.)

Rozanov V. Semiya kak religiya. In: Rozanov V. V. V mire neyasnogo i nereshennogo. Moscow, 1995, p. 67-81. (in Russ.)

Ure A. Vasilii Rozanov and the Creation: The Edenic Vision and the Rejection of Eschatology. London, New York: Continuum, 2011.

Vitgenstein L. Logiko-filosofskiy traktat. Transl. from Germ. by I. S. Dobronravov, D. M. Lakhuti. Moscow, 1958. (in Russ.)

DOI 10.25205/2307-1737-2019-1-10-25 